\title{
CORRELAÇÕES ENTRE CARACTERÍSTICAS MORFOGÊNICAS E ESTRUTURAIS EM PASTOS DE CAPIM-BRAQUIÁRIA
}

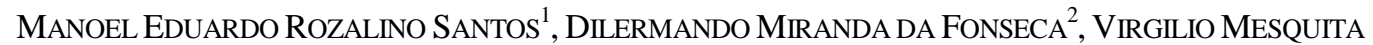

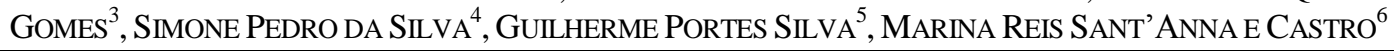 \\ ${ }^{1}$ Professor doutor da Universidade Federal de Uberlândia, Uberlândia, MG, Brasil. m_rozalino@yahoo.com.br \\ ${ }^{2}$ Professor Doutor da Universidade Federal de Viçosa, Viçosa, MG, Brasil. \\ ${ }^{3}$ Professor Doutor da Universidade Estadual de Montes Claros, Montes Claros, MG, Brasil. \\ ${ }^{4}$ Doutoranda em em Zootecnia pela Universidade Estadual Paulista na área de Nutrição de Ruminantes, Jaboticabal, SP, Brasil. \\ ${ }^{5}$ Graduado em Agronomia pela Universidade Federal de Viçosa, Viçosa, MG, Brasil. \\ ${ }^{6}$ Graduada em Zootecnia pela Universidade Federal de Viçosa, Viçosa, MG, Brasil.
}

A análise conjunta das características morfogênicas e estruturais do pasto permite compreender os padrões de respostas das plantas ao ambiente. Dessa forma, este trabalho foi conduzido para avaliar as associações entre as características morfogênicas e estruturais da Brachiaria decumbens sob lotação contínua com bovinos. Foi avaliado o desenvolvimento de perfilhos individuais em pastos mantidos sob duas estratégias de manejo do pastejo, durante três estações do ano (inverno, primavera e verão). Correlações lineares de Pearson entre as variáveis respostas foram estimadas. Os comprimentos da lâmina foliar e do colmo, os números de perfilhos e de folhas vivas por perfilho, as taxas de aparecimento foliar e de alongamento de folha e de colmo da $B$. decumbens foram positivamente correlacionados. Houve relação negativa entre aparecimento e duração de vida das folhas $(r=-0,89)$. Porém, correlações positivas entre taxa de aparecimento foliar e número de perfilho $(\mathrm{r}=0,64)$ e entre comprimento do colmo e taxa de senescência foliar $(\mathrm{r}=0,63)$ foram determinadas. A $B$. decumbens modifica sua morfogênese para melhor adaptação às condições do clima e do manejo do pastejo.

PALAVRAS-CHAVE: Brachiaria decumbens; clima; crescimento; pastejo; senescência.

\section{CORRELATIONS BETWEEN STRUCTURAL AND MORPHOGENETIC CHARACTERISTICS ON SIGNALGRASS PASTURES}

\section{ABSTRACT}

The analysis of both morphogenetic and structural characteristics of pasture allows us to understand the response patterns of the plant to the environment. Thus, this study was conducted to evaluate the associations between the morphogenetic and structural characteristics of Brachiaria decumbens under continuous grazing by cattle. The development of individual tillers in pastures was evaluated under two grazing management strategies during three seasons (winter, spring and summer). Pearson correlations between variables were estimated. The lengths of leaf and stem, number of tillers and leaves per tiller, rates of leaf appearance and elongation of leaf and stem of B. decumbens were positively correlated. There was a negative relationship between appearance and lifespan of leaves $(r=-0.89)$. However, positive correlations between leaf appearance rate and number of tillers $(r=0.64)$ and between length of stem and leaf senescence rate $(r=0.63)$ were determined. The B. decumbens modifies its morphogenesis to better adapt to climate and grazing management.

KEYWORDS: Brachiaria decumbens; climate, grazing; growth; senescence.

\section{INTRODUÇÃO}

A perenidade e a produtividade do pasto decorrem da contínua emissão de folhas e perfilhos, processos importantes para a restauração da área foliar após desfolhação. O desenvolvimento de folhas é fundamental para o crescimento vegetal, dado o papel das folhas na fotossíntese, ponto de partida para a síntese de tecidos (PARSONS et al., 1983). 
O desenvolvimento do colmo também influencia a produção de forragem porque, dependendo do estádio de desenvolvimento do perfilho, o colmo tem prioridade na partição de fotoassimilados. Ademais, o colmo pode favorecer à fotossíntese do dossel pela redução do seu coeficiente de extinção de luz (FAGUNDES et al., 2001).

O melhor entendimento da dinâmica de produção de forragem no pasto pode ser obtido pelo estudo da morfogênese. Em pastos onde apenas folhas são produzidas, a morfogênese de plantas pode ser descrita por três características principais: taxa de aparecimento foliar, taxa de alongamento foliar e duração de vida da folha. A combinação das características morfogênicas determina as três principais características estruturais do pasto: tamanho da folha, densidade populacional de perfilhos e número de folhas vivas por perfilho (CHAPMAN \& LEMAIRE, 1993).

Vale salientar que, em pastos tropicais, o alongamento do colmo também é característica morfogênica importante, pois determina outras características estruturais que influenciam decisivamente a produção primária e secundária da pastagem, tais como o tamanho do colmo (SANTOS et al., 2011) e a relação lâmina foliar/colmo (CÂNDIDO et al., 2005).

As alterações nas características morfogênicas da planta determinam modificações nas características estruturais do pasto, ou seja, alteram a forma como os órgãos da parte aérea da planta são arranjados no tempo e no espaço. Isso altera o microclima (e. g.: ventilação, temperatura, umidade, luminosidade) no qual as plantas se desenvolvem e, como consequência, gera novas mudanças no padrão morfogênico da planta. Todos esses processos caracterizam a complexa e interdependente natureza da dinâmica de populações de plantas e do fluxo de tecidos no ecossistema pastagem. Desse modo, o estudo de correlações é importante porque identifica a natureza das associações entre as variáveis da morfogênese do vegetal.

Adicionalmente, a interpretação das respostas morfogênicas da planta possibilita averiguar se o manejo do pastejo sazonal, caracterizado pela adoção de alturas de pasto diferenciadas entre as estações do ano, é vantajoso, quando comparado ao manejo do pastejo semelhante entre as estações do ano.

Assim, este trabalho foi desenvolvido com o objetivo de avaliar a associação entre características morfogênicas e estruturais da Brachiaria decumbens manejada em lotação contínua durante três estações do ano.

\section{MATERIAL E MÉTODOS}

O experimento foi realizado de junho de 2008 a março de 2009 em área de pastagem de Brachiaria decumbens cv. Basilisk (Stapf.) (capim-braquiária), pertencente ao Setor de Forragicultura do Departamento de Zootecnia da Universidade Federal de Viçosa, em Viçosa-MG (204' S; 4251' W; 651 m). Foi utilizada uma pastagem de capim-braquiária estabelecida em Latossolo Vermelho-Amarelo de textura argilosa e relevo medianamente ondulado (EMBRAPA, 1999). Antes da implementação deste experimento, a pastagem já se encontrava dividida em oito piquetes, de 0,25 a 0,40 ha, além de uma área de reserva, totalizando aproximadamente 3,0 ha.

O clima da região de Viçosa, de acordo com o sistema de Köppen (1948), é do tipo Cwa, com precipitação anual em torno de $1.340 \mathrm{~mm}$ e umidade relativa do ar média de $80 \%$. As temperaturas médias máxima e mínima são de 22,1 e $15^{\circ} \mathrm{C}$. Os dados climáticos registrados durante o período experimental foram obtidos na estação meteorológica do Departamento de Engenharia Agrícola da UFV, situada a cerca de $500 \mathrm{~m}$ da área experimental (Tabela 1).

Tabela 1- Médias mensais da temperatura média diária, insolação, precipitação pluvial total mensal e evaporação total mensal de junho de 2008 a março de 2009

\begin{tabular}{lcccc}
\hline Mês & $\begin{array}{c}\text { Temperatura média } \\
\text { do } \operatorname{ar}\left({ }^{\circ} \mathrm{C}\right)\end{array}$ & $\begin{array}{c}\text { Insolação } \\
\text { (hora/dia) }\end{array}$ & $\begin{array}{c}\text { Precipitação pluvial } \\
\text { (mm) }\end{array}$ & $\begin{array}{c}\text { Evaporação } \\
\text { (mm) }\end{array}$ \\
\hline Junho/2008 & 16,7 & 6,2 & 12,7 & 55,9 \\
Julho/2008 & 15,4 & 8,2 & 10,2 & 73,9 \\
Agosto/2008 & 16,7 & 7,3 & 15,4 & 87,1 \\
Setembro/2008 & 18,7 & 4,4 & 150,0 & 101,5 \\
Outubro/2008 & 21,6 & 5,6 & 41,4 & 89,0 \\
Novembro/2008 & 21,0 & 3,7 & 223,8 & 65,8 \\
Dezembro/2009 & 21,3 & 11,1 & 626,0 & 270,8 \\
Janeiro/2009 & 22,5 & 13,2 & 250,7 & 137,0 \\
Fevereiro/2009 & 23,0 & 6,6 & 222,5 & 63,3 \\
Março/2009 & 22,8 & 5,8 & 231,9 & 60,1 \\
\hline
\end{tabular}


Foram avaliadas duas estratégias de manejo do pastejo. Em uma, o pasto foi mantido com $25 \mathrm{~cm}$ de altura média durante todo o período experimental. A outra correspondeu à manutenção do pasto em 15 $\mathrm{cm}$ de altura média durante o inverno, com aumento para $25 \mathrm{~cm}$ a partir do início da primavera. Adotouse o esquema de parcelas subdivididas e o delineamento em blocos casualizados com quatro repetições. As estratégias de manejo do pastejo corresponderam ao fator primário (parcela), caracterizadas pelas alturas médias em que os pastos foram mantidos sob lotação contínua durante as estações do ano: inverno, primavera e verão. Essas corresponderam ao fator secundário (subparcela) e consistiram de medidas ao longo do período experimental.

Desde junho de 2007, os oito piquetes da área experimental vinham sendo manejados sob lotação contínua com taxa de lotação variável para manter a altura média do pasto em $25 \mathrm{~cm}$. Dessa forma, para a implementação dos tratamentos, em meados de junho de 2008, os quatro piquetes descritos anteriormente tiveram a altura média do pasto rebaixada para $15 \mathrm{~cm}$. Para isso, aumentou-se a taxa de lotação nos mesmos, utilizando-se bovinos em recria com peso médio de aproximadamente 200 kg. Assim, conseguiu-se que, em um período de cerca de 15 dias, as metas de alturas $(15 \mathrm{~cm})$ fossem alcançadas. Por outro lado, os outros quatros piquetes permaneceram com o pasto em cerca de 25 $\mathrm{cm}$ de altura média, com ausência de animais desde maio de 2008. Somente a partir do início de outubro de 2008 todos os piquetes voltaram a ser utilizados, concomitantemente, com animais, e os pastos foram manejados sob lotação contínua e taxa de lotação variável para manter sua altura média em aproximadamente $25 \mathrm{~cm}$.

O monitoramento das alturas dos pastos foi realizado por meio de medidas em 50 pontos de cada piquete, utilizando-se instrumento e metodologia descritos por SANTOS et al. (2011). Para o controle da altura do pasto, bovinos com cerca de $200 \mathrm{~kg}$ de peso corporal foram retirados ou colocados nos piquetes quando as alturas dos pastos estavam abaixo ou acima, respectivamente, do valor almejado.

O manejo da adubação foi feito com base na análise química do solo realizada em outubro de 2008, que apresentou os seguintes resultados: $\mathrm{pH}$ em $\mathrm{H}_{2} \mathrm{O}: 4,79$; P: 1,5 (Mehlich-1) e $\mathrm{K}: 86 \mathrm{mg} / \mathrm{dm}^{3} ; \mathrm{Ca}^{2+}$ : 1,$46 ; \mathrm{Mg}^{2+}: 0,32 \mathrm{e} \mathrm{Al}^{3+}: 0,19 \mathrm{cmol}_{\mathrm{C}} / \mathrm{dm}^{3}(\mathrm{KCl} 1$ mol/L). Foi realizada adubação em toda área experimental com a aplicação de $100 \mathrm{~kg} / \mathrm{ha}$ de $\mathrm{N}$ e $\mathrm{K}_{2} \mathrm{O}$, bem como $25 \mathrm{~kg} / \mathrm{ha}$ de $\mathrm{P}_{2} \mathrm{O}_{5}$, usando-se $\mathrm{o}$ formulado 20-05-20. Essas doses foram divididas em duas aplicações iguais, que ocorreram nos dias 11/11/2008 e 15/12/2008.

Desde o início de julho de 2008 até o fim de março de 2009, as características morfogênicas e estruturais do capim-braquiária foram avaliadas em 16 perfilhos por unidade experimental, de acordo com metodologia descrita por SANTOS et al. (2011). A partir desses procedimentos foram calculadas as variáveis: taxa de aparecimento foliar, filocrono, taxa de alongamento foliar, taxa de alongamento de colmo, taxa de senescência foliar, duração de vida da folha, comprimento da lâmina foliar, comprimento do colmo, números de folhas vivas e mortas por perfilho e número de perfilhos por área.

O banco de dados gerado com essas avaliações de morfogênese (SANTOS et al., 2011) foi utilizado para o estudo de associação entre as características morfogênicas e estruturais do capimbraquiária. As análises dos dados experimentais foram feitas usando o Sistema para Análises Estatísticas - SAEG, versão 8.1 (UFV, 2003). Correlações lineares de Pearson entre as características morfogênicas e estruturais foram estimadas utilizando-se 24 observações. Todos os valores foram testados pelo teste $\mathrm{t}$ a até $10 \%$ de probabilidade.

\section{RESULTADOS E DISCUSSÃO}

Os valores das características morfogênicas e estruturais do capim-braquiária (Tabela 2), utilizados para o estudo de correlação neste trabalho, permitiram evidenciar que o rebaixamento do pasto para $15 \mathrm{~cm}$ no inverno resultou em maior taxa de aparecimento foliar e superiores números de folha viva e de perfilhos durante essa estação. Todavia, essa estratégia de manejo fez com que a duração de vida da folha, a taxa de senescência foliar e os comprimentos da lâmina foliar e do pseudocolmo fossem menores no inverno em relação ao pasto com $25 \mathrm{~cm}$. Ademais, no inverno houve taxas de aparecimento e alongamento foliar inferiores, menores taxas de alongamento de colmo, menor número de folha viva e de perfilhos e comprimentos da lâmina foliar e do pseudocolmo inferiores. Por outro lado, a duração de vida da folha e o número de folhas mortas foram superiores no inverno. $\mathrm{O}$ maior valor de taxa de senescência foliar ocorreu na primavera. Assim, o pasto de B. decumbens cv. Basilisk, sob lotação contínua, pode ser manejado de forma sazonal, com seu rebaixamento para $15 \mathrm{~cm}$ no início do inverno e seu posterior aumento para $25 \mathrm{~cm}$ no início da primavera (SANTOS et al., 2011). 
Tabela 2- Características morfogênicas e estruturais em pastos de capim-braquiária manejados sob lotação contínua e com altura fixa ou variável durante as estações do ano

\begin{tabular}{lcccccc}
\hline \multirow{2}{*}{ Característica } & \multicolumn{3}{c}{$\begin{array}{c}\text { Pasto com 25 cm em } \\
\text { todas as estações }\end{array}$} & \multicolumn{3}{c}{$\begin{array}{c}\text { Pasto com } 15 \text { cm no inverno e } \\
25 \mathrm{~cm} \text { na primavera e verão }\end{array}$} \\
\cline { 2 - 7 } & Inverno & Primavera & Verão & Inverno & Primavera & Verão \\
\hline TApF & 0,01 & 0,10 & 0,11 & 0,02 & 0,11 & 0,12 \\
FIL & 80,74 & 10,48 & 8,88 & 52,99 & 9,17 & 8,05 \\
TAlC & 0,01 & 0,24 & 0,30 & 0,01 & 0,23 & 0,35 \\
TAlF & 0,10 & 1,35 & 1,61 & 0,12 & 1,52 & 1,41 \\
TSeF & 0,34 & 0,51 & 0,25 & 0,18 & 0,29 & 0,19 \\
DVF & 147,87 & 39,19 & 38,31 & 129,69 & 33,16 & 34,77 \\
CLF & 10,33 & 13,15 & 13,34 & 6,95 & 12,08 & 13,85 \\
CC & 18,26 & 23,55 & 19,55 & 8,70 & 16,97 & 20,05 \\
NFM & 2,13 & 1,76 & 1,16 & 1,94 & 1,62 & 1,16 \\
NFV & 2,39 & 4,81 & 5,38 & 3,42 & 4,64 & 5,46 \\
NP & 1578 & 1697 & 1951 & 1665 & 1980 & 2213 \\
\hline
\end{tabular}

TApF- taxa de aparecimento foliar; FIL- filocrono; TAlF- taxa de alongamento foliar; TAlC- taxa de alongamento de colmo; TSeFtaxa de senescência foliar; DVF- duração de vida da folha; CLF- comprimento da lâmina foliar; CC- comprimento do colmo; NFVnúmero de folha viva; NFM- número de folha morta; NP- número de perfilho.

No que tange à associação entre as características morfogênicas do capim-braquiária, a taxa de aparecimento foliar (TApF) correlacionou-se de forma positiva com as taxas de alongamento foliar (TAlF) e de colmo (TAlC), porém sua correlação com a duração de vida da folha foi negativa (Tabela 3). Esses resultados podem ser explicados levando-se em consideração as condições climáticas durante o período experimental (Tabela 1).

Tabela 3- Correlações lineares de Pearson entre características morfogênicas de perfilhos em pastos de capim-braquiária sob lotação contínua

\begin{tabular}{ccccccc}
\hline Variável & TApF & FIL & TAlF & TAlC & TSeF & DVF \\
\hline TApF & - & $-0,94^{*}$ & $0,97^{*}$ & $0,94^{* *}$ & 0,07 & $-0,89^{* *}$ \\
FIL & & - & $-0,92^{*}$ & $-0,86^{* *}$ & 0,08 & $0,94^{*}$ \\
TAlF & & & - & $0,93^{*}$ & 0,16 & $-0,86$ \\
TAlC & & & & - & 0,07 & $-0,80^{* * *}$ \\
TSeF & & & & & - & $-0,17$ \\
DVF & & & & & & - \\
\hline
\end{tabular}

TApF- taxa de aparecimento foliar; FIL- filocrono; TAlF- taxa de alongamento foliar; TAlC- taxa de alongamento de colmo; TSeFtaxa de senescência foliar; DVF- duração de vida da folha; *Significativo pelo teste $\mathrm{t}(\mathrm{P}<0,01)$; **Significativo pelo teste $\mathrm{t}(\mathrm{P}<0,05)$; $* * *$ Significativo pelo teste $\mathrm{t}(\mathrm{P}<0,10)$.

Nos meses com clima favorável ao crescimento do pasto (outubro a março), o fluxo de tecidos de perfilhos individuais foi intenso, razão da associação positiva entre a TApF e os demais índices de crescimento do pasto (TAlF e TAlC). Por outro lado, as condições de clima adversas durante o inverno (Tabela 1), tais como menor temperatura, ínfima precipitação pluvial e reduzida insolação, limitaram o desenvolvimento de perfilhos e causaram redução concomitante nas TApF, TAlF e TAlC. Na verdade, as taxas de crescimento de tecidos respondem imediatamente às mudanças de temperatura do meio, de forma que a produção de tecidos segue suas variações sazonais (FAGUNDES et al., 2006; MORAES et al., 2006).

A relação negativa entre TApF e duração de vida da folha (DVF) (Tabela 3) evidencia um mecanismo compensatório no pasto de capimbraquiária em resposta aos fatores abióticos. No inverno, há condições restritivas para o crescimento do pasto devido, dentre outros fatores, ao decréscimo da disponibilidade de nutrientes para a planta forrageira em decorrência, principalmente, do déficit hídrico ocorrido nessa época do ano, o que limita a 
absorção de nutrientes pela planta via fluxo de massa e difusão no solo (NOVAES \& SMYTH, 1999). Nessas condições, o capim-braquiária reduz sua taxa de crescimento, apresentando menores TApF, TAlF e TAlC. Entretanto, como forma de contrabalancear esses efeitos adversos à formação da nova área foliar do pasto, o capim-braquiária incrementou a DVF. Isso permitiu o aumento do tempo médio de permanência dos nutrientes na planta $\mathrm{e}$, por conseguinte, melhorou a conservação dos mesmos no organismo vegetal (SANTOS et al., 2011).

É oportuno ressaltar que a eficiência na conservação dos nutrientes, conferida pela maior DVF do capim-braquiária, é apropriada quando o ambiente é caracterizado por menor ocorrência de desfolhação (SANTOS et al., 2011), fato que aconteceu no inverno, estação em que os pastos de capim-braquiária permaneceram sem animais, devido à necessidade de manutenção das alturas pretendidas.

Contrariamente, na primavera e no verão, estações em que os fatores ambientais de crescimento foram restabelecidos (Tabela 1) e épocas em que foram realizadas as adubações, a maximização do crescimento (maiores TApF, TAlF e TAlC) resultou em redução da DVF. De fato, a baixa DVF tem sido reconhecida como marcador de resposta de plantas relacionado à condição de meio favorável ao crescimento, como alta fertilidade do solo (WRIGHT et al., 2004).

As correlações do filocrono com as demais características morfogênicas foram contrárias àquelas verificadas para a $\mathrm{TApF}$ (Tabela 3), o que é coerente, haja vista que o filocrono corresponde ao inverso da TApF.
Com relação à taxa de senescência foliar (TSeF), suas correlações foram fracas e não significativas com as demais características morfogênicas do capim-braquiária (Tabela 3). Esses resultados podem ser justificados pela instabilidade inerente ao processo de senescência foliar. Ademais, enquanto as demais características morfogênicas apresentaram padrões de respostas típicos e diferenciados entre os meses de inverno e os de primavera e verão, a TSeF foi alta apenas durante a primavera, apresentando valores reduzidos no inverno e também no verão (SANTOS et al., 2011).

Como as características morfogênicas determinam as características estruturais da planta (CHAPMAN \& LEMAIRE, 1993), torna-se relevante conhecer a associação entre essas variáveis respostas. Nesse sentido, verificou-se que, de modo geral, aquelas características estruturais descritoras do maior crescimento do pasto (comprimento da lâmina foliar, comprimento do colmo, número de folha viva por perfilho, número de perfilhos) estiveram positivamente correlacionadas com as características morfogênicas que denotam maior fluxo de tecidos da planta (taxas de aparecimento foliar e de alongamento de folha e de colmo) (Tabela 4). Isso ocorreu porque os valores dessas variáveis foram aumentados, de forma conjunta, nos meses do ano com condições climáticas favoráveis ao crescimento do pasto.

Esses resultados estão de acordo com aqueles obtidos por SANTOS et al. (2010), que verificaram que o peso do perfilho de capimbraquiária sob lotação contínua foi positivamente correlacionado com as suas taxas de alongamento de folha $(r=+0,64)$ e de colmo $(r=+0,63)$.

Tabela 4- Correlações lineares de Pearson entre características morfogênicas e estruturais de perfilhos em pastos de capim-braquiária sob lotação contínua

\begin{tabular}{cccccc}
\hline Variável & CLF & CC & NFV & NFM & NP \\
\hline TApF & $0,84^{* *}$ & $0,59 * * *$ & $0,93^{*}$ & $-0,70^{* *}$ & $0,64 * * *$ \\
FIL & $-0,70^{* *}$ & $-0,47^{* * *}$ & $-0,91^{*}$ & $0,67 * * *$ & $-0,57 * * *$ \\
TAlF & $0,84^{* *}$ & $0,62^{* * *}$ & $0,90^{*}$ & $-0,68^{* * *}$ & $0,58^{* * *}$ \\
TAlC & $0,87 * *$ & $0,66^{* *}$ & $0,91 *$ & $-0,73 * *$ & $0,61 * * *$ \\
TSeF & 0,29 & $0,63 * * *$ & $-0,08$ & 0,41 & 0,33 \\
DVF & $-0,72$ & $-0,57 * * *$ & $-0,77 * *$ & $0,59 * * *$ & $-0,49 * * *$ \\
\hline
\end{tabular}

TApF- taxa de aparecimento foliar; FIL- filocrono; TAlF- taxa de alongamento foliar; TAlC- taxa de alongamento de colmo; TSeFtaxa de senescência foliar; DVF- duração de vida da folha; CLF- comprimento da lâmina foliar; CC- comprimento do colmo; NFVnúmero de folha viva; NFM- número de folha morta; NP- número de perfilho; *Significativo pelo teste $\mathrm{t}(\mathrm{P}<0,01)$; **Significativo pelo teste $\mathrm{t}(\mathrm{P}<0,05)$; ***Significativo pelo teste $\mathrm{t}(\mathrm{P}<0,10)$.

Por outro lado, o número de folhas mortas por perfilho correlacionou-se de modo positivo com aquelas variáveis respostas que denotam menor fluxo de tecidos e inferior taxa de crescimento da planta, tais como filocrono e duração de vida da folha (Tabela 4). Isso ocorreu porque os valores dessas variáveis foram aumentados, conjuntamente, nos meses do ano com clima desfavorável ao crescimento do pasto. 
É oportuno sublinhar a associação positiva entre a TApF e o número de perfilho do capimbraquiária (Tabela 4). Esse resultado é justificado considerando-se que a maior TApF é premissa para o aparecimento de perfilhos no pasto. Em outras palavras, quando uma nova folha é sintetizada, há a formação concomitante de uma nova gema axilar, com potencial de originar um perfilho (NELSON, 2000). Dessa forma, o incremento da TApF nos meses de clima favorável (Tabela 1) pode estimular o perfilhamento do pasto, o que assegura sua estabilidade e sua produção de forragem.

Outras relações positivas e coerentes ocorreram entre a TAlF e o CLF, bem como entre a TAlC e o CC (Tabela 4). De fato, a maior síntese e/ou alongamento celular ocorrido nos órgãos do vegetal, especialmente nos meses com clima predisponente ao crescimento e desenvolvimento do pasto, concorre para incrementar o tamanho desses órgãos. De fato, BRAZ et al. (2010) verificaram aumento linear do comprimento da lâmina foliar do capim-braquiária em função da sua taxa de alongamento foliar, bem como incremento linear do comprimento do colmo em resposta à elevação da sua taxa de alongamento.

Conforme já foi discutido, a TSeF não apresentou correlações $(\mathrm{P}>0,10)$ com a maioria das características estruturais do capim-braquiária. $\mathrm{Na}$ verdade, apenas o comprimento do colmo esteve positivamente correlacionado com a TSeF (Tabela 4). Em geral, em pastos tropicais, algumas condições em que ocorre maior senescência foliar também resultam em perfilhos com colmo mais compridos, e uma dessas condições é o sombreamento no interior do dossel, comum em pastos com maior altura média, tal como aquele manejado neste trabalho com $25 \mathrm{~cm}$ no inverno (SANTOS et al., 2011). Sob sombreamento, as lâminas foliares, principalmente as mais velhas e de menor nível de inserção no perfilho, atingem o ponto de compensação luminoso e senescem (HODGSON, 1990). Ao mesmo tempo, o sombreamento desencadeia elevada competição por luz entre os perfilhos, levando a planta a priorizar a alocação de carbono para o alongamento dos entrenós, a fim de posicionar a nova área foliar nas camadas menos sombreadas do dossel (CARNEVALLI et al., 2006).

Esses argumentos também foram utilizados por BRAZ et al. (2010) para justificar a correlação positiva da taxa de senescência foliar com a taxa de alongamento do colmo em plantas de capim-braquiária com alturas variáveis no mesmo pasto manejado em lotação contínua com bovinos.

Embora não tenha ocorrido $(\mathrm{P}>0,10)$, era esperada a correlação positiva entre a TSeF e o número de folhas mortas por perfilho (Tabela 4). Isso pode ter acontecido em virtude da metodologia empregada neste trabalho, em que somente quando o processo de senescência ultrapassava mais de 50\% do comprimento das lâminas foliares, as folhas eram consideradas mortas. Desse modo, em muitos casos, houve a mensuração da senescência foliar apenas na porção apical das lâminas foliares, porém muitas folhas continuaram a ser classificadas como vivas.

No tocante às associações entre as características estruturais do capim-braquiária, constatou-se que o comprimento da lâmina foliar (CLF) correlacionou de forma positiva com o comprimento do colmo (CC) (Tabela 5). Comparativamente ao pasto mantido em $15 \mathrm{~cm}$ no inverno, aquele manejado com maior altura $(25 \mathrm{~cm})$ apresentou plantas que possuíam perfilhos com colmo mais comprido durante o inverno e a primavera (SANTOS et al., 2011). Nesses perfilhos maiores, as folhas mais novas precisam fazer maior percurso no pseudocolmo para se expor. Com isso, a distância percorrida pela folha desde o ponto de conexão com o meristema até a extremidade do pseudocolmo é maior, resultando no seu maior comprimento (SKINNER \& NELSON, 1995).

De modo geral, as correlações foram positivas entre as características estruturais que se referem ao número e tamanho dos órgãos vivos dos perfilhos, quais sejam: CLF, CC, número de folhas vivas (NFV) e número de perfilho (NP). Por outro lado, essas características correlacionaram-se negativamente com o número de folhas mortas por perfilho (NFM) (Tabela 5).

Tabela 5- Correlações lineares de Pearson entre características estruturais de perfilhos em pastos de capimbraquiária sob lotação contínua

\begin{tabular}{cccccc}
\hline Variável & CLF & CC & NFV & NFM & NP \\
\hline CLF & - & $0,85^{*}$ & $0,73^{* * *}$ & $-0,61 * * *$ & 0,46 \\
CC & & - & 0,43 & $-0,26$ & 0,14 \\
NFV & & & - & $-0,79 * *$ & $0,58^{* * *}$ \\
NFM & & & & - & $-0,56^{* * *}$ \\
NP & & & & -
\end{tabular}

CLF- comprimento da lâmina foliar; CC- comprimento do colmo; NFV- número de folhas vivas; NFM- número de folhas mortas; NP- número de perfilho; * Significativo pelo teste $\mathrm{t}(\mathrm{P}<0,01)$; ** Significativo pelo teste $\mathrm{t}(\mathrm{P}<0,05)$; *** Significativo pelo teste $\mathrm{t}$ $(\mathrm{P}<0,10)$. 
Nos meses de primavera e verão, os órgãos da parte aérea dos perfilhos (folhas e colmos) expressaram maiores taxas de crescimento (SANTOS et al., 2011) e, desse modo, alcançaram maiores comprimentos. Da mesma forma, os NFV e NP também foram elevados nessas estações do ano em razão das condições climáticas favoráveis ao desenvolvimento da planta. Por isso, as correlações entre essas variáveis foram positivas (Tabela 5). Nesse sentido, SANTOS et al. (2010), em trabalho com plantas de capim-braquiária com alturas variáveis no mesmo pasto, também constataram que as correlações foram positivas entre o peso do perfilho e os comprimentos da lâmina foliar $(\mathrm{r}=$ $0,66)$ e do colmo $(r=0,82)$, e o número de folhas vivas por perfilho $(r=0,69)$.

Todavia, o menor NFM durante as estações em que o pasto apresentou maior crescimento e tamanho dos seus órgãos (primavera e verão) (SANTOS et al., 2011) justifica a correlação negativa do NFM com as demais características estruturais. Provavelmente, em virtude do maior comprimento das lâminas foliares durante a primavera e o verão, as folhas levaram mais tempo para apresentarem mais de $50 \%$ de senescência e, com isso, menos folhas foram consideradas mortas.

Os dados apresentados permitem inferir que o capim-braquiária modifica suas características morfogênicas e estruturais de maneira dinâmica e interativa como forma de adaptação às condições variáveis do ambiente, incluindo o clima e o manejo do pastejo. Nesse sentido, o estudo de correlações permitiu identificar a natureza das relações ou associações entre as variáveis respostas obtidas pela avaliação morfogênica, o que é de grande valia para melhor compreensão das respostas das plantas forrageiras no ecossistema de pastagem.

\section{CONCLUSÃO}

O manejo do pastejo, concebido de forma sazonal por meio do rebaixamento do pasto de capim-braquiária para $15 \mathrm{~cm}$ no início do inverno e seu posterior aumento para $25 \mathrm{~cm}$ no início da primavera, foi vantajoso, quando comparado à manutenção do pasto em altura fixa $(25 \mathrm{~cm}$, em média) durante as estações do ano.
Os tamanhos e os números dos órgãos da parte aérea da Brachiaria decumbens cv. Basilisk, bem como suas taxas de crescimento são positivamente correlacionados.

No pasto de $B$. decumbens sob lotação contínua ocorrem as seguintes relações: 1) compensação entre aparecimento e duração de vida das folhas; 2) correlação positiva entre taxa de aparecimento foliar e número de perfilho; e 3) associação positiva entre comprimento do colmo e taxa de senescência foliar.

A $B$. decumbens modifica sua morfogênese para adaptação às condições variáveis do ambiente, incluindo o clima e o manejo do pastejo.

\section{REFERÊNCIAS}

BRAZ, T.G.S.; SANTOS, M.E.R.; GOMES, V.M.; CASTRO, M.R.S.; FONSECA, D.M. Interdependência entre características do fluxo de tecidos do capimbraquiária. Enciclopédia Biosfera, v.6, n.10, p.1-12. 2010.

CÂNDIDO, M.J.D.; GOMIDE, C.A.M.; ALEXANDRINO, E.; GOMIDE, J.A.; PEREIRA, W.E. Morfofisiologia do Dossel de Panicum maximum cv. Mombaça sob Lotação Intermitente com Três Períodos de Descanso. Revista Brasileira de Zootecnia, v.34, n.2, p.406-415. 2005.

CARNEVALLI, R. A.; DA SILVA, S. C.; BUENO, A. A. O.; UEBELE, M. C.; BUENO, F. O.; SILVA, G. N.; MORAES, J. P. Herbage production and grazing losses in Panicum maximum cv. Mombaça under four grazing managements. Tropical Grasslands, v. 40, n. 3, p. 165-176, 2006.

CHAPMAN, D.F., LEMAIRE, G. Morphogenetic and structural determinants of plant regrowth after defoliation. In: BAKER, M. J. (Ed.). Grasslands for Our World. SIR Publishing, Wellington, p.55-64, 1993.

EMBRAPA. Sistema brasileiro de classificação dos solos. Brasília: Embrapa-SPI; Rio de Janeiro: EmbrapaCNPS, 1999. 412p.

FAGUNDES, J.A.; SILVA, S.C.; PEDREIRA, C.G.S.; CARNEVALLI, R.A.; CARVALHO, C.A.B.; SBRISSIA, A.F.; PINTO, L.F.M. Índice de área foliar, coeficiente de extinção luminosa e acúmulo de forragem em pastagens de Cynodon spp. sob lotação contínua. Pesquisa Agropecuária Brasileira, v.36, n.1, p. 871-195, 2001.

FAGUNDES, J.A.; FONSECA, D.M.; MISTURA, C.; MORAES, R.V.; VITOR, C.M.T.; GOMIDE, J.A.; NASCIMENTO JUNIOR, D.; CASAGRANDE, D.R.; COSTA, L.T. Características morfogênicas e estruturais 
do capim-braquiária em pastagem adubada com nitrogênio avaliadas nas quatro estações do ano. Revista Brasileira de Zootecnia, v.35, n.1, p.21-29, 2006.

HODGSON, J. Grazing management - science into practice. Essex: Longman Scientific \& Technical, 1990, 203p.

KÖPEN, W. Climatologia. Buenos Aires: Gráfica Panamericana, 1948.478p.

MORAES, R.V.; FONSECA, D.M.; NASCIMENTO JR.; RIBEIRO JR, J.I.; FAGUNDES, J.L.; MOREIRA, L.M.; MISTURA, C.; MARTUSCELLO, J.A. Demografia de perfilhos basilares em pastagem de Brachiaria decumbens adubada com nitrogênio. Revista Brasileira de Zootecnia, v.35, n.2, p.380-388, 2006.

NELSON, C.J. Shoot Morphological Plasticity of Grasses: Leaf Growth vs. Tillering. In: LEMAIRE, G.; HODGSON, J.; CARVALHO, P.C.F.; NABINGER, C. (Eds.) Grassland ecophysiology and grazing ecology. CAB-International, Wallingford, UK, p.101-126, 2000.

NOVAES, R.F.; SMYTH, T.J. Fósforo em solo e em condições tropicais. Viçosa: UFV, DPS, 1999. 399p.

PARSONS, A. J. The effects of season and management on the growth of grass swards. In: JONES, M. B.; LAZENBY, A. (Ed.). The grass crop: the physiological basis of production. London: Chapman and Hall, 1988. p. 129-177.

SANTOS, M.E.R.; FONSECA, D.M.; SILVA, S.P.; GOMES, V.M.; ALBINO, R.L. Associações entre características morfogênicas e estruturais do capimbraquiária com alturas variáveis no mesmo pasto. Enciclopédia Biosfera, v.6, n.10, p.1-10. 2010.

SANTOS, M.E.R.; FONSECA, D.M.; GOMES, V.M.; GOMIDE, C.A.M.; NASCIMENTO JR, D.; QUEIROZ, D.S. Capim-braquiária sob lotação contínua e com altura única ou variável durante as estações do ano: morfogênese e dinâmica de tecidos. Revista Brasileira de Zootecnia, v.40, n.11, p.2323-2331. 2011.

SKINNER, R.H., NELSON, C.J. Elongation of the grass leaf and its relationship to the phyllochron. Crop Science, v.35, n.1, p.4-10. 1995.

WRIGHT, I. J.; REICH; WESTOBY, M. et al. 2004. The worldwide leaf economics spectrum. Nature 428:821-827.

UNIVERSIDADE FEDERAL DE VIÇOSA - UFV. SAEG - Sistema de análises estatísticas e genéticas. Versão 8.1. Viçosa, MG: 2003. (Apostila). 